\title{
Posterior short-segment fixation with implanting pedicle screw in the fractured level as a feasible method for treatment of thoracolumbar fracture
}

\author{
Mohammed Mustafa Adawi*, Islam Aboulfetouh, Ahmed Saleh and Walid Younis
}

\begin{abstract}
Background: The thoracolumbar spine is vulnerable to fracture in falls or motor vehicle accidents. Thoracolumbar spine fracture can be associated with neurological deficits, long-term pain and disability. The optimal management for these injuries remains a considerable subject for research.

Objectives: To evaluate short-term surgical and functional outcome of posterior short-segment fixation with implanting pedicle screw in the fractured level (short same-segment fixation) for treatment of recent single-level traumatic thoracolumbar fracture.

Methods: This prospective study included 36 patients with radiologically confirmed single-level thoracolumbar fracture. Patients were evaluated preoperatively, at time of discharge, and at follow-up visit after 1 year clinically using the Low-Back Outcome Scale of Greenough and Fraser Score, the American Spinal Injury Association (ASIA) for neurological evaluation, and the AO fracture classification for injury severity evaluation. Radiological evaluation included calculation of the sagittal index (SI) of injured vertebral body, anterior body compression (ABC) according to Mumford's equation, and regional kyphosis using Cobb angle. All patients underwent posterior trans-pedicular screw insertions into a vertebral body one level above and below the fracture site, and an additional pedicle screw was inserted at the level of the fracture. Postoperative clinical and radiological evaluations were compared to the preoperative.
\end{abstract}

Results: All surgeries were conducted uneventfully within $129.7 \pm 33.9$ min with mean operative blood loss of 351.4 $\pm 140.5 \mathrm{ml}$. Wound infection was encountered in two patients and responded to conservative treatment. Mean duration of postoperative hospital stay and follow-up were $17.7 \pm 4.4$ days and $26.5 \pm 5.1$ months, respectively. After 1 year, mean low-back pain scores were significantly higher than preoperative and early postoperative scores and frequency of patients with excellent-good postoperative status was significantly higher at early postoperative evaluation and after 1 year compared to the preoperative status. Eight patients had neurological deficit, after 1-year follow-up; six patients were improved by one grade, while the other two cases remained stationary. Mean SI and ABC calculated at discharge and after 1 year were significantly higher compared to the preoperative measures. Mean Cobb angle was significantly decreased compared to the preoperative angle. Mean improvement of kyphosis angle at discharge and after 1 year was $60.9 \%$ and $48.1 \%$, respectively; however, there was loss of kyphosis correction by about $4.2^{\circ}$ after 1 -year follow-up compared to the early postoperative finding.

(Continued on next page)

\footnotetext{
*Correspondence: moh.adawi@yahoo.com

Department of Neurosurgery, Benha University, Benha, Egypt
} 
(Continued from previous page)

Conclusion: Posterior short same-segment trans-pedicular screws fixation of single-level traumatic thoracolumbar fracture provided satisfactory surgical and functional outcome with minimal loss of postoperative Cobb angle and vertebral height, without loss of more motion segments.

Keywords: Traumatic spinal fractures, Trans-pedicular fixation, Posterior approach

\section{Background}

Improved knowledge of the anatomic, morphometric, and biomechanical features of thoracolumbar (TL) vertebrae allowed progress and improvement of management of unstable TL fractures that remained and still controversial [1].

Controversy exists about the best treatment of unstable TL burst fractures. Conservative treatment is usually the method of choice if there is little kyphotic deformity, no neurological deficit, or no unstable fracture pattern. Kyphosis correction and canal decompression in case of a neurological deficit are recognized treatment objectives, and surgical strategies have been proposed [2].

Surgical treatment of spine fractures aims to achieve bony union and restore spinal anatomy. A number of techniques have been described for the management of spinal fractures. Surgical treatment of spine fractures may associate, as needed, decompression, reduction, and graft and/or internal fixation, using a posterior, anterior, or combined approach [3].

Approach for surgical correction is still a point of debate; anterior, posterior, or combined anterior and posterior procedures have been advocated and show various degrees of success [4]. On the basis of biomechanical considerations such as the load-sharing concept and tension-band principle, reconstruction of the anterior column with dorsal compression osteosynthesis instrumentation is the treatment of choice. A combined approach in one stage has the preference in comparison with a staged procedure [3]. Paraspinal approach is safe with the advantages of micro-trauma and less blood loss $[5,6]$.

Minimizing the number of vertebral levels involved in fusion of a spine fracture is a common goal of internal fixation. This is achievable by utilizing traditional short-segment posterior fixation; however, a 54\% incidence of instrument failure or unfavorable clinical outcome was encountered with traditional short-segment posterior fixation [7].

Short-segment posterior fixation with pedicle fixation at the level of the fracture (short same-segment fixation) suggests biomechanical advantages toward maintenance of kyphosis correction and reducing failure rates [8]. The trans-pedicular short same-segment construct represents an attempt to rebuild the anterior column without the need for anterior strut graft or plate fixation, hence, avoiding extensive arthrodesis of the motion segments and limited surgery-related injury [9].

The current prospective study aimed to evaluate the short-term surgical and functional outcome of posterior short-segment fixation with implanting pedicle screw in the fractured level (short same-segment fixation) for treatment of recent single-level traumatic thoracolumbar fracture.

\section{Main text}

\section{Patients and methods}

The current study was conducted on 36 patients at the Neurosurgery Department Benha university hospitals and in the central hospitals of the Ministry of Health Kingdom of Saudia Arabia, since December 2013 till September 2016 to allow a minimum follow-up period of 12 months after the surgery for the last case operated upon. The study intended to include patients with recent, traumatic single-level thoracolumbar fracture (T10-L2); patients with multi-level fracture, delayed surgery for any cause, or patients with head injury or any other indications for ICU admission were excluded from the study.

\section{Preoperative evaluation}

\section{Clinical evaluation}

(a) Patients' demographic data, mechanism of injury, injury-surgery interval, extent and site of injury, and type of fracture were evaluated.

(b) Low-back pain and its impact on quality of life was evaluated using the Low-Back Outcome Scale of Greenough and Fraser Score [10] with its 13 factors; total score is the sum of points for all of the 13 parameters, where score of $\geq 65$ indicated excellent, 50-64 indicated good, 30-49 indicated fair, and 0-29 indicated poor patients status.

(c) Preoperative neurological deficit was assessed using the American Spinal Injury Association (ASIA) scoring as shown in Table 1 [11].

(d) The severity of the injury in terms of instability was expressed by its ranking within the $\mathrm{AO}$ fracture classification consists of three types: A, B, and C. Every type has three groups, each of which contains three subgroups with specifications according to the 
Table 1 American Spinal Injury Association classification ${ }^{11}$

\begin{tabular}{ll}
\hline Grade & Neurologic deficit \\
\hline A $\quad \begin{array}{l}\text { No sensory or motor function is preserved in sacral segments } \\
\text { S4-S5 }\end{array}$ & $\begin{array}{l}\text { Sensory, but not motor function is preserved below the } \\
\text { neurologic level and extends through sacral segments S4-S5 }\end{array}$ \\
C $\quad \begin{array}{l}\text { Motor function is preserved below the neurologic level and } \\
\text { most key muscles below the neurologic level have muscle grade } \\
\text { less than 3. }\end{array}$ \\
D $\quad \begin{array}{l}\text { Motor function is preserved below the neurologic level and } \\
\text { most key muscles below the neurologic level have muscle grade } \\
\text { greater than or equal to 3. }\end{array}$ \\
E Sensory and motor functions are normal
\end{tabular}

mechanism acting on the spine compression, distraction, and axial torque [12].

2. Radiological evaluation: Patients were evaluated with plain radiographs, CT scan, and magnetic resonance imaging and the following parameters were evaluated:

1. The sagittal index (SI) of the injured vertebral body was calculated using the ratio between the anterior and the posterior height of the vertebral wall: $\mathrm{SI}=\mathrm{hA} / \mathrm{hP}$ [13].

2. Anterior body compression $(\mathrm{ABC})$ was measured according to Mumford's anterior body compression equation [14].

3. Regional kyphosis (Cobb angle) was measured on the lateral radiograph as the angle between the inferior end plate of the intact vertebra above the fracture to the superior end plate of the intact vertebra below the fracture [15].

4. The ratio of canal compromise was measured on the axial CT scan as the difference between the pre-injury canal size and the canal size after injury, as a ratio of the pre-injury canal size. The pre-injury canal size was determined by averaging the canal sizes above and below the fracture level [16].

\section{Surgical indications}

Surgical indications included neurological involvement caused by the fracture, $\geq 20^{\circ}$ kyphosis, $>50 \%$ loss of the vertebral body's height, and $>50 \%$ compromised spinal canal.

\section{Surgical method}

Standard posterior spinal approach was performed in all cases. Poly-axial pedicle screws were inserted into a vertebral body one level above and below the fractured vertebra. Additional pedicle screw was inserted through the fractured vertebra. Fixation was achieved with connecting rods producing distraction and lordosis. After connecting rods and pedicle screws, distraction force was applied using spreader forceps to create tension of the posterior longitudinal ligament, to reduce the fracture by ligamentotaxis. To confirm the reduction of the fracture, the lateral view of the fluoroscopy was used to demonstrate a "one-line sign" of the posterior wall of the vertebrae at the fracture level. Posterior-lateral synostosis was performed with bone fragment with autologous bone graft harvested from the spinous processes or iliac crest in eight cases. Rehabilitation program was started once the patients' postoperative status stabilized. All patients were protected by a brace for 3 months.

\section{Evaluations of outcome}

\section{Primary outcome involves the following:}

- Radiological evaluation of preoperatively evaluated parameters at time of hospital discharge and at follow-up visit after 1 year.

- Low-back pain scoring estimated at time of hospital discharge and after 1 year.

- Neurological assessment to evaluate ASIA grades at 1-year follow-up.

\section{Secondary outcome involves the following:}

- Operative data including operative time, amount of intraoperative blood loss and frequency of intraoperative complications.

- The frequency of postoperative complications, required lines of management, and its outcome and total postoperative hospital stay.

- Patients' satisfaction with the procedure was assessed with a 4-point scale questionnaire, ranging from 4 points (very satisfied) to 1 point (very dissatisfied).

\section{Results}

The study included 36 patients; 26 males and 10 females with a range of $20-52$ years. Mechanism of injury varied, but road traffic accident was the commonest. Mean injury-surgery interval was $4.8 \pm 1.6$, range 28 days. According to the $\mathrm{AO}$ classification, the majority of injuries were of type A. Details of patients' enrolment data are shown in Table 2.

All surgeries were conducted uneventfully without intraoperative complications within $129.7 \pm 33$.9, range 75 $190 \mathrm{~min}$; however, the majority of cases were operated 
Table 2 Enrolment data of studied patients

\begin{tabular}{|c|c|c|c|}
\hline \multicolumn{3}{|l|}{ Data } & \multirow{2}{*}{$\begin{array}{l}\text { Findings } \\
22(61.1 \%)\end{array}$} \\
\hline \multirow[t]{4}{*}{ Age (years) } & \multirow[t]{3}{*}{ Strata } & $<40$ & \\
\hline & & $40-49$ & $8(22.2 \%)$ \\
\hline & & $\geq 50$ & $6(16.7 \%)$ \\
\hline & \multicolumn{2}{|l|}{ Total } & $44.3 \pm 1.6$ \\
\hline \multirow[t]{2}{*}{ Gender } & \multicolumn{2}{|l|}{ Males } & $26(72.2 \%)$ \\
\hline & \multicolumn{2}{|l|}{ Females } & $10(27.8 \%)$ \\
\hline \multirow[t]{3}{*}{ Mechanism of injury } & \multicolumn{2}{|c|}{ Road traffic accident } & $20(55.6 \%)$ \\
\hline & \multicolumn{2}{|l|}{ Fall from height } & $12(33.3 \%)$ \\
\hline & \multicolumn{2}{|c|}{ Hit by falling objects } & $4(11.1 \%)$ \\
\hline \multicolumn{3}{|c|}{ Injury-surgery interval (days) } & $4.8 \pm 1.6$ \\
\hline \multirow{2}{*}{\multicolumn{2}{|c|}{ Injury segmental distribution }} & Thoracic (T0-T12) & $10(27.8 \%)$ \\
\hline & & Lumbar (L1-L2) & $26(72.2 \%)$ \\
\hline \multirow[t]{6}{*}{ Type of fracture } & \multirow{4}{*}{$\begin{array}{l}\text { Type A } \\
\text { (Compression) }\end{array}$} & $\mathrm{A} 1$ & $4(11.1 \%)$ \\
\hline & & $A 2$ & $12(33.3 \%)$ \\
\hline & & A3 & $10(27.8 \%)$ \\
\hline & & Total & $26(72.2 \%)$ \\
\hline & \multicolumn{2}{|c|}{ Type B (Distraction) } & $6(16.7 \%)$ \\
\hline & \multicolumn{2}{|c|}{ Type C (Rotation) } & $4(11.1 \%)$ \\
\hline
\end{tabular}

upon through 90-150 min. Mean operative blood loss was $351.4 \pm 140.5$, range $150-650 \mathrm{ml}$; blood loss in majority of patients was in a range of $250-500 \mathrm{ml}$.

No postoperative complications occurred apart from back wound infection that was encountered in two patients and responded to conservative treatment. Donor site complication was encountered in four cases, in whom iliac crest bone graft was harvested, in the form of wound infection in two cases treated conservatively and local pain improved gradually within 3 months in two cases. Mean postoperative hospital stay was $17.7 \pm$ 4.4, range 10-24 days. Majority of patients (66.7\%) had hospital stay for < 15 days. Mean postoperative follow-up was $22.5 \pm 5.1$, range $18-36$ months. Details of operative and postoperative data are shown in Table 3.

Mean low-back pain scores determined at 1 year were significantly $(p<0.05)$ higher compared to scores determined preoperatively and at time of discharge, also scores at time of discharge were significantly ( $p$ $<0.05$ ) higher compared to scores determined preoperatively. The frequency of patients with excellentgood postoperative status was significantly higher at time of discharge and after 1 year compared to the preoperative status.

Preoperative neurological evaluation according to ASIA grades showed neurological deficit in only eight patients (22.2\%), four patients were of grade D and two of each of grades B and C. At end of follow-up, six
Table 3 Operative and postoperative data of studied patients

\begin{tabular}{|c|c|c|c|}
\hline Data & & & Findings \\
\hline \multirow[t]{6}{*}{ Operative time (min) } & \multirow[t]{5}{*}{ Strata } & $60-90$ & $4(11.1 \%)$ \\
\hline & & $>90-120$ & $12(33.3 \%)$ \\
\hline & & $>120-150$ & $10(27.8 \%)$ \\
\hline & & $>150-180$ & $6(16.7 \%)$ \\
\hline & & $>180$ & $4(11.1 \%)$ \\
\hline & Total & & $\begin{array}{l}129.7 \pm 33.9(75- \\
190)\end{array}$ \\
\hline \multirow{4}{*}{$\begin{array}{l}\text { Operative blood loss } \\
\text { (ml) }\end{array}$} & \multirow[t]{3}{*}{ Strata } & $<250$ & $8(22.2 \%)$ \\
\hline & & $250-500$ & $24(66.7 \%)$ \\
\hline & & $>500$ & $4(11.1 \%)$ \\
\hline & Total & & $\begin{array}{l}351.4 \pm 140.5(150- \\
650)\end{array}$ \\
\hline \multirow[t]{3}{*}{ PO complications } & Yes & $\begin{array}{l}\text { Donor area } \\
\text { complications }\end{array}$ & $4(11.1 \%)$ \\
\hline & & Back wound infection & $2(5.5 \%)$ \\
\hline & No & & $30(83.4 \%)$ \\
\hline \multirow{3}{*}{$\begin{array}{l}\text { PO hospital stay } \\
\text { (days) }\end{array}$} & Strata & $>15$ & $12(33.3 \%)$ \\
\hline & & $\leq 15$ & $24(66.7 \%)$ \\
\hline & Total & & $17.7 \pm 4.4(10-24)$ \\
\hline Follow-up (months) & & & $22.5 \pm 5.1$ \\
\hline
\end{tabular}

Data are presented as numbers \& mean $\pm \mathrm{SD}$; percentages \& ranges are in parenthesis

patients were improved by one grade, while two patients of grade D remained stationary. There was no significant $(p>0.05)$ difference between studied patients throughout times of evaluation as regards the frequency of ASIA grades.

Mean ratio between height of the anterior and posterior walls of the injured vertebra (Saggital index) estimated at time of discharge was significantly $(p<0.05)$ higher compared to preoperative index. At the end of follow-up, the SI decreased again but was still significantly $(p<0.05)$ higher compared to preoperative index and not significantly $(p>0.05)$ lower compared to SI estimated at time of discharge. Mean anterior body compression calculated at time of discharge was significantly $(p<0.05)$ lower compared to preoperative index. At the end of follow-up, mean $\mathrm{ABC}$ increased again but was still significantly $(p<0.05)$ more than preoperative $\mathrm{ABC}$ and not significantly $(p>0.05)$ less than that estimated at time of discharge.

Mean Cobb angle was significantly $(p<0.05)$ decreased at time of discharge and at the end of follow-up on radiological evaluation compared to preoperative angle. Mean improvement of kyphosis angle at time of discharge and at the end of follow-up was $60.9 \%$ and $48.1 \%$, respectively (Fig. 1). Despite the significant $(p<0.05)$ improvement of Cobb angle at end of follow-up, there was loss of kyphosis correction by about $4.2^{\circ}$ compared to angle estimated at 


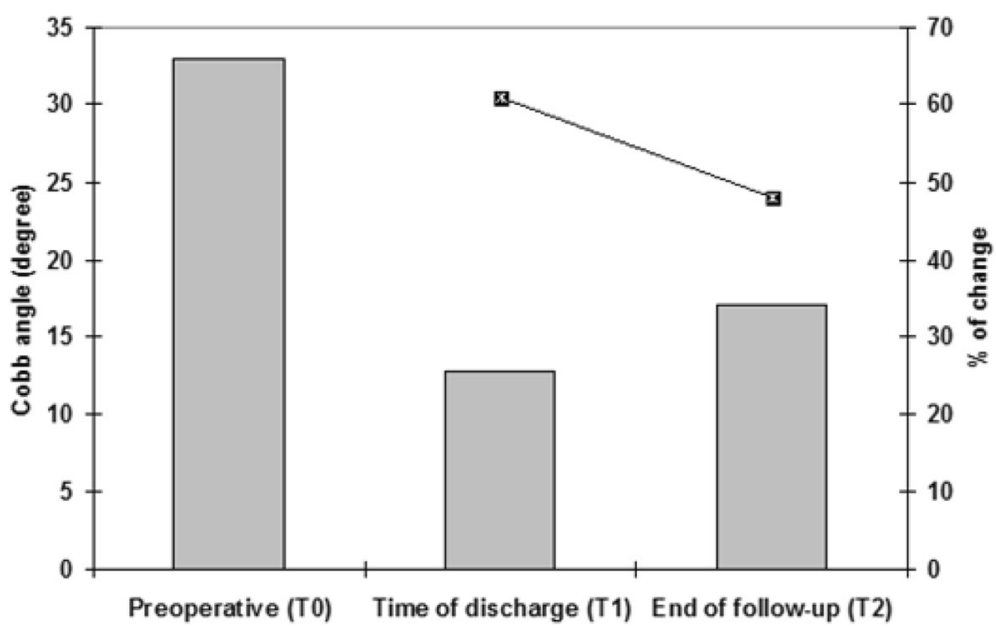

Fig. 1 Kyphosis angle estimated radiologically at time of discharge and at the end of follow-up compared to preoperative angle

time of discharge. Ratio of canal compromise was significantly $(p<0.05)$ decreased at time of discharge and end of follow-up on radiological evaluation compared to preoperative ratio with non-significant difference in favor of at end of follow-up (Table 4).

Eight patients were very satisfied by the final outcome that is excellent, 22 patients were satisfied, four patients were dissatisfied, and only two patients were very dissatisfied by the final outcome secondary to absence of improvement.

\section{Illustrative cases}

In case 1, a traumatized patient presented by L2 fracture; the patient was neurologically intact and was treated with short same-segment technique. The postoperative course was uneventful with satisfactory outcome at time of discharge and at the end of follow-up (Fig. 2).

In case 2, a traumatized patient was presented with severe back pain, urgent $\mathrm{CT}$ revealed $\mathrm{L} 1$ fracture. $\mathrm{Pa}-$ tient was operated by short same-segment technique (Fig. 3).

Table 4 Clinical and radiological evaluation data determined at time of discharge and at end of follow-up

\begin{tabular}{|c|c|c|c|c|c|}
\hline \multirow{2}{*}{\multicolumn{6}{|c|}{$\frac{\text { Data }}{\text { Clinical findings }}$}} \\
\hline & & & & & \\
\hline \multirow[t]{7}{*}{ Low back pain score } & \multicolumn{2}{|l|}{ Mean score $( \pm S D)$} & $25.7 \pm 4$ & $35.4 \pm 3.6^{\mathrm{a}}$ & $49.4 \pm 4.8^{\mathrm{ab}}$ \\
\hline & \multirow[t]{2}{*}{ Frequency of improvement } & $<50 \%$ & & $20(55.6 \%)$ & $10(27.8 \%)$ \\
\hline & & $>50 \%$ & & $18(44.4 \%)$ & $26(72.2 \%)^{b}$ \\
\hline & \multirow[t]{4}{*}{ Patients' status } & Excellent & 0 & $4(11.1 \%)$ & $6(16.7 \%)$ \\
\hline & & Good & $4(22.2 \%)$ & $12(33.3 \%)^{\mathrm{a}}$ & $20(55.6 \%)^{a}$ \\
\hline & & Fair & $9(50 \%)$ & $16(44.5 \%)$ & $8(22.2 \%)$ \\
\hline & & Poor & $5(27.8 \%)$ & $4(11.1 \%)$ & $2(5.5 \%)$ \\
\hline \multirow[t]{5}{*}{ ASIA grades } & \multicolumn{2}{|l|}{ A } & 0 & 0 & 0 \\
\hline & \multicolumn{2}{|l|}{ B } & $2(5.5 \%)$ & 0 & 0 \\
\hline & \multicolumn{2}{|l|}{ C } & $2(5.5 \%)$ & $2(5.5 \%)$ & 0 \\
\hline & \multicolumn{2}{|l|}{ D } & $4(11.1 \%)$ & $4(11.1 \%)$ & $4(11.1 \%)$ \\
\hline & \multicolumn{2}{|l|}{$E$} & $28(77.9 \%)$ & $30(83.4 \%)$ & $32(88.9 \%)$ \\
\hline \multicolumn{6}{|l|}{ Radiological findings } \\
\hline \multicolumn{3}{|l|}{ Sagittal index (SI) } & $0.7 \pm 0.13$ & $0.8 \pm 0.11^{a}$ & $0.78 \pm 0.09^{a}$ \\
\hline \multicolumn{3}{|c|}{ Extent of anterior body compression } & $0.42 \pm 0.2$ & $0.24 \pm 0.14^{\mathrm{a}}$ & $0.23 \pm 0.19^{a}$ \\
\hline \multicolumn{3}{|l|}{ Cobb angle $\left(^{\circ}\right)$} & $33 \pm 5$ & $12.8 \pm 3.3^{\mathrm{a}}$ & $17.1 \pm 4.3^{\mathrm{ab}}$ \\
\hline \multicolumn{3}{|c|}{ Ratio of canal compromise } & $12.2 \pm 8.3$ & $4.4 \pm 3.9^{\mathrm{a}}$ & $2.8 \pm 3.6^{a}$ \\
\hline
\end{tabular}

Data are presented as numbers \& mean \pm SD; percentages are in parenthesis; FU: Follow-up; ${ }^{\text {a }}$ significance of difference versus preoperative data; ${ }^{\text {b }}$ significance of difference versus at time of discharge data; ASIA American Spinal Injury Association 

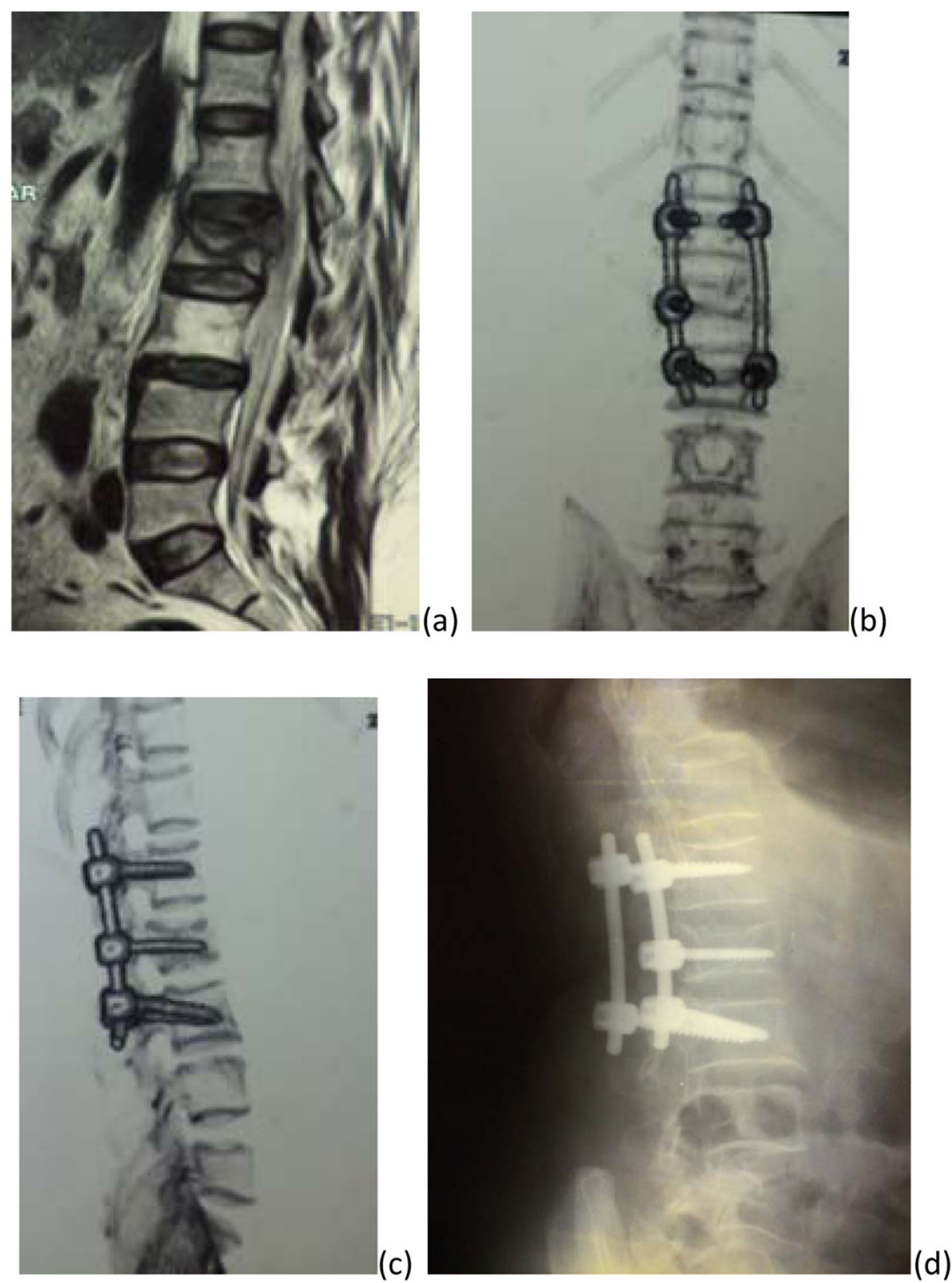

Fig. 2 (a) Pre-operative sagittal MRI T2WI showing unstable fracture of $L 2$ with retropused fragment, (b) Early post-operative $C T$, 3D reconstruction, anterior view showing 2 screws in L1, 2 screws in L3, and 1 screw in L2, (c) Early post-operative CT, 3D reconstruction, sagittal view showing screws in place with adequate reduction of retropused fragment, (d) X-ray lumbar spine, lateral view performed 1 year after surgery showing nearly maintained kyphosis angel

\section{Discussion}

Evaluation of spinal trauma-related data revealed that fall from height was the commonest mechanism of injury, and injury at thoracolumbar junction was encountered in $72.2 \%$ of cases and the majority of injuries were of type A. Similarly, Kalicinski et al. [17] reported that the most common causes of traumatic spinal injuries are falls from a height and road accidents and fractures occur most often at the thoracolumbar junction of the spine.
Mean operative time was about 130 min with mean intraoperative blood loss of $350 \mathrm{ml}$, no intraoperative complications were encountered, but two patients developed postoperative wound infection that responded to conservative treatment and mean postoperative hospital stay was about 18 days. These data goes in hand with Feng et al. [18] who studied 16 severe thoracolumbar fracture dislocations treated with a pedicle screw system via an entirely posterior approach and reported that mean operation time was 

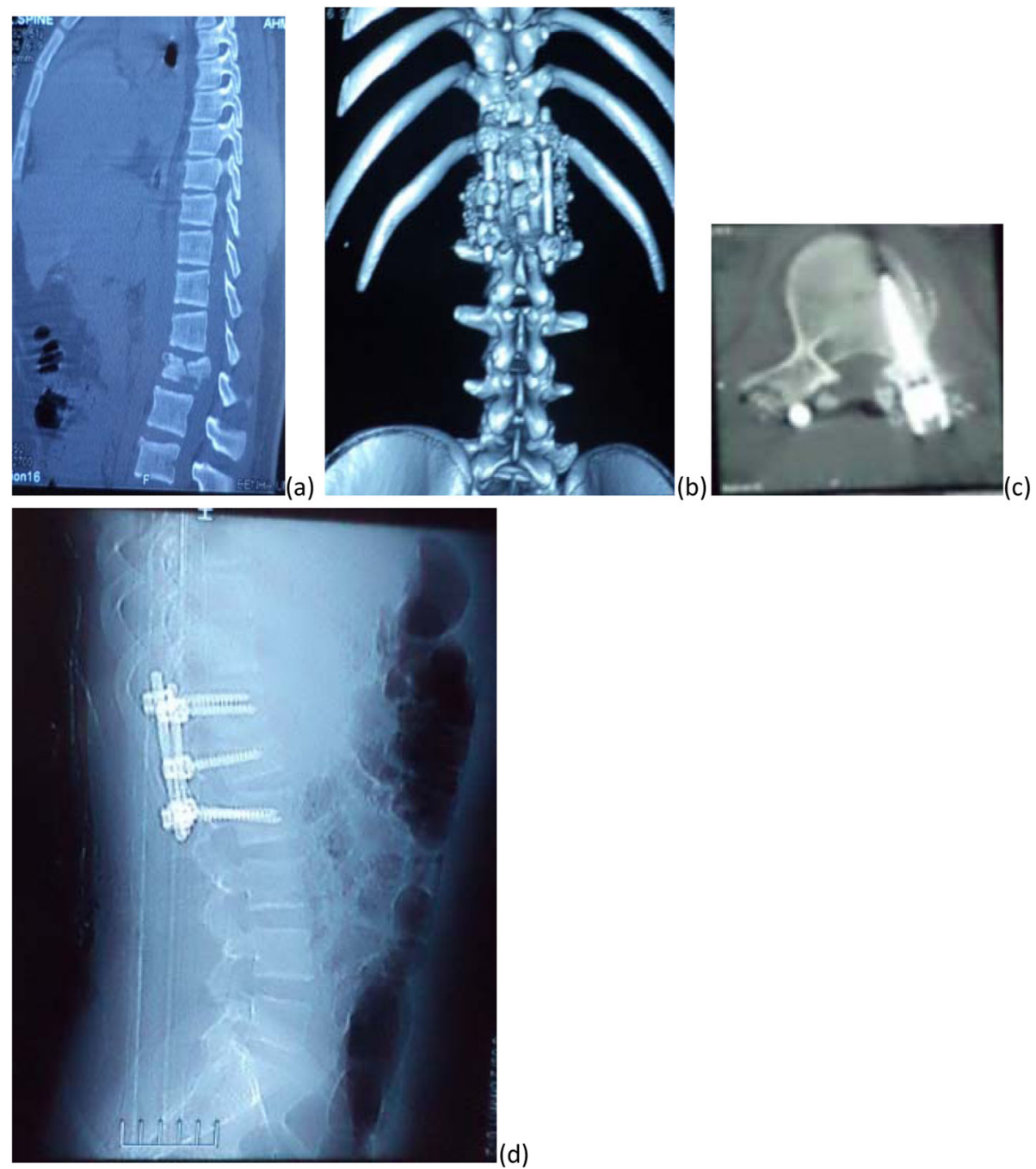

(d)

Fig. 3 (a) Pre-operative sagittal CT showing fracture of L1, b) Early post-operative CT, 3D reconstruction, posterior view showing 2 screws in D12, 2 screws in L2, and 1 screw in L1. (note: bone graft on each side of the rods) (c) Axial cuts showing single screw on the left side of L1, (d) X-ray lumbar spine, lateral view performed 1 year after surgery showing stable construct

170 min (range 120-280), and mean blood loss was $700 \mathrm{ml}$.

The current study reported favorable surgical and functional outcome for posterior short same-segment trans-pedicular screw fixation; with posterolateral bone grafting. Outcome was manifested clinically as significant improvement of low-back pain outcome score with significantly higher frequency of patients had excellent-to-good status. Radiological evaluation revealed significant decrease of kyphotic angle and extent of anterior body compression with significantly increased vertebral body height manifested as increased sagittal index. Neurological evaluation showed improvement of ASIA grade by 1 grade in six of the eight patients having neurological affection, but the other two patients showed stationary course. The maneuver and approach applied in the current study provided good spinal stability throughout a mean follow-up duration of about 27 months with non-significant difference in radiological findings at end of follow-up compared to findings at time of discharge.

The modern treatment of thoracolumbar fractures is based on posterior trans-pedicular fixation techniques, which are angular stable and can provide an excellent stability in the three planes of the space. Nevertheless, a widely accepted agreement and clear guidelines for the optimal treatment of thoracolumbar fractures are lacking, and the evidence is based above all on School or Individual "Philosophies" for the management of this pathology [19].

Short segment pedicle screw fixation, involving one vertebra above and one vertebra below the fracture level, has become the most common method in the 
treatment of thoracolumbar burst fractures. It provides the benefits of decreased involvement of motion segments than fixation with longer instrumentation. However, many studies have reported loss of kyphosis correction and implant failure following short-segment fixation [20].

Increasing the fixation level is hypothesized to decrease the stress on each pedicle screw and so minimize the chance of failure. This may be achieved by use of long-segment constructs, but this requires fusing of multiple motion segments and larger incisions, with an increased risk of complications. An alternative method is to include screws at the level of the fracture [21].

In support of the short same-segment fixation, Mahar et al. [22], in cadaveric study reported increased biomechanical stability of short-segment fixation with additional pedicle fixation at the level of fracture (short same-segment fixation). Subsequently, Guven et al. [23] clinically showed increased stability and long-term maintenance with short same-segment fixation. Bolesta et al. [21] documented that a short segment construct with pedicle screws at the fracture site showed equivalent biomechanical stability compared with a conventional long-segment construct in any of the loading conditions.

Also, Kanna et al. [24] found that reduction of unstable thoracolumbar injuries can be achieved and maintained with the use of short-segment pedicle screw fixation including the fractured vertebra and resulted in significant improvement of preoperative kyphotic angle and wedge angle with significant improvement of anterior and posterior vertebral height.

The advantages of using pedicle screws to treat fractured vertebrae include the following: (i) it provides a good three-point fixation to reduce the suspension effect of the internal fixation system, (ii) it reduces the parallelogram effect to increase the stability, (iii) it avoids stretching the normal intervertebral disc, which is beneficial to the recovery of the vertebral fracture form, and (iv) it dispenses the stress of the pedicle screw connection. Therefore, conditional application of vertical stress screw fixation of fractured vertebrae enhances the stability of the posterior short-segment internal fixation system for thoracolumbar fractures and facilitates the correction of kyphosis and maintenance of the corrective effect [25].

Rehabilitation program was started once the patients' status stabilized. All patients were protected by a Taylor brace for 3 months. Early ambulation and rehabilitation showed no deleterious effects on fracture fixation but allowed maintenance or even more improvement concerning low-back scoring and patients' status at the end of follow-up. In line with these findings, Özlürk et al. [26] found that conservative treatment of stable thoracolumbar burst fractures is widely accepted and early mobilization with customized brace appears to produce effective functional results despite loss of vertebral body height.

\section{Conclusion}

It could be concluded that posterior short same-segment trans-pedicular screws fixation is a viable option for treatment of single-level traumatic thoracolumbar fracture provided satisfactory surgical and functional outcome with minimal loss of postoperative Cobb angle and vertebral height at end of follow-up, without loss of more motion segments. A large sample study with a longer follow-up is recommended.

\section{Abbreviations}

ABC: Anterior Body Compression; ASIA: American Spinal Injury Association; $C T$ scan: Computed tomography scan; L1: First lumbar vertebra; L2: Second lumbar vertebra; SI: Sagittal Index; TL: Thoracolumbar

\section{Acknowledgements}

No other person contributed to this article.

Funding

No funding was received for this research.

Availability of data and materials

The datasets are available from the corresponding author on request.

\section{Authors' contributions}

All authors shared in making the study design and in the collection, analysis, and interpretation of data. Surgical operations for the studied group were performed by the authors. All authors have been involved in revising the manuscript and approved the final version. The idea of the study was related to Mohammed Adawi. Review of literature was the responsibility of Mohammed Adawi with the help of other authors.

\section{Ethics approval and consent to participate}

All procedures performed in studies involving human participants were in accordance with the ethical standards of the Research Ethics Committee of the Faculty of Medicine, Benha University, that retrospectively approved the study on 6, March, 2018.

All participants provided informed written consent to participate in the study.

Consent for publication

Not applicable

\section{Competing interests}

The authors declare that they have no competing interests.

\section{Publisher's Note}

Springer Nature remains neutral with regard to jurisdictional claims in published maps and institutional affiliations.

Received: 13 October 2017 Accepted: 9 December 2018

Published online: 25 January 2019

\section{References}

1. Malhotra D, Kalb S, Rodriguez-Martinez N, Hem DD, Perez-Orribo L, Crawford NR, Sonntag VK. Instrumentation of the posterior thoracolumbar spine: from wires to pedicle screws. Neurosurgery. 2014;10(Suppl 4):497-505.

2. Payer M. Unstable burst fractures of the thoraco-lumbar junction: treatment by posterior bisegmental correction/fixation and staged anterior corpectomy and titanium cage implantation. Acta Neurochir. 2006;148(3):299-306.

3. Allain J. Anterior spine surgery in recent thoracolumbar fractures: an update. Orthop Traumatol Surg Res. 2011;97(5):541-54.

4. Cui H, Guo J, Yang L, Guo Y, Guo M. Comparison of therapeutic effects of anterior decompression and posterior decompression on thoracolumbar 
spine fracture complicated with spinal nerve injury. Pak J Med Sci. 2015; 31(2):346-50.

5. Han L, Quan RF, Sun GR, Bi DW, Wang H, Zu G. Treatment of thoracolumbar fractures with unilateral pedicle screw fixation through paraspinal approach. Zhongguo Gu Shang. 2014;27(5):395-9.

6. He SH, Ma DJ, Sun ZT, Yu WJ, Wang YG. Internal fixation combined with bone grafting through the injured pedicle for the treatment of thoracolumbar burst fractures via a paraspinal intermuscular approach under MAST Quadrant retractor. Zhongguo Gu Shang. 2015;28(1):17-20.

7. Eno JJ, Chen JL, Mitsunaga MM. Short same-segment fixation of thoracolumbar burst fractures. Hawaii J Med Public Health. 2012;71(1):19-22.

8. Kose KC, Inanmaz ME, Isik C, Basar H, Caliskan I, Bal E. Short segment pedicle screw instrumentation with an index level screw and cantilevered hyperlordotic reduction in the treatment of type-A fractures of the thoracolumbar spine. Bone Joint J. 2014;96-B(4):541-7.

9. Sun GR, Han L. Treatment of thoracolumbar fractures with short-segment transpediclar screw fixation and vertebroplasty via paraspinal intermuscular approach. Zhongguo Gu Shang. 2014;27(2):97-100.

10. Greenough CG, Fraser RD. Assessment of outcome in patients with lowback pain. Spine (Phila Pa 1976). 1992;17(1):36-41.

11. Priebe MM, Waring WP. The interobserver reliability of the revised American Spinal Injury Association standards for neurological classification of spinal injury patients. Am J Phys Med Rehabil. 1991;70:268-70.

12. Magerl F, Aebi M, Gertzbein SD, Harms J, Nazarian S. A comprehensive classification of thoracic and lumbar injuries. Eur Spine J. 1994;3(4):184-201.

13. Farcy JP, Veidenbaum M, Glassman S. Sagittal index in management of thoracolumbar burst fractures. Spine. 1990;15:958-65.

14. Mumford J, Weinstein JN, Spratt KF, Goel VK. Thoracolumbar burst fractures: the clinical efficacy and outcome of nonoperative management. Spine. 1993;18:955-70

15. Patrick T, Russel CH, Christian AL, Dominque GP, Rene PL. Functional and radiologic outcome of thoracolumbar and burst fractures managed by closed orthopaedic reduction and casting. Spine. 2003;28:2459-65.

16. Carlisle E, Luna M, Tsou PM, Wang JC. Percent spinal canal compromise on MRI utilized for predicting the need for surgical treatment in single-level lumbar intervertebral disc herniation. Spine J. 2005;5(6):608-14.

17. Kalicińnki M, Szzześniak A, Kalisz J, Tęsiorowski M. Anterior fixation of thoracolumbar traumatic spinal injuries. Ortop Traumatol Rehabil. 2015;17(1):7-20.

18. Feng Z, Xiaoqing C, Xiangdong C, Junjie G, Xingjie J, Yu Y, Ming L, Jian Z, Yong C. Surgery for severe thoracolumbar fracture dislocation via a posterior approach. J Clin Neurosci. 2015;(15):00383-5.

19. Martiniani M, Vanacore F, Meco L, Specchia N. Is posterior fixation alone effective to prevent the late kyphosis after T-L fracture. Eur Spine J. 2013; 22(Suppl 6):951-95.

20. Altay M, Ozkurt B, Aktekin CN, Ozturk AM, Dogan O, Tabak AY. Treatment of unstable thoracolumbar junction burst fractures with short- or long-segment posterior fixation in Magerl type a fractures. Eur Spine J. 2007;16(8):1145-55.

21. Bolesta MJ, Caron T, Chinthakunta SR, Vazifeh PN, Khalil S. Pedicle screw instrumentation of thoracolumbar burst fractures: biomechanical evaluation of screw configuration with pedicle screws at the level of the fracture. International Journal of Spine Surgery. 2012;6:200-5.

22. Mahar A, Kim C, Wedemeyer M, Mitsunaga L, Odell T, Johnson B, Garfi n S. Short-segment fixation of lumbar burst fractures using pedicle fixation at the level of the fracture. Spine. 2007;32(14):1503-7.

23. Guven O, Kocaoglu B, Bezer M, Aydin N, Nalbantoglu U. The use of screw at the fracture level in the treatment of thoracolumbar burst fractures. I Spinal Disord. 2009:22(6):417-21.

24. Kanna RM, Shetty AP, Rajasekaran S. Posterior fixation including the fractured vertebra for several unstable thoracolumbar fractures. Spine J. 2015;15(2):256-64

25. Huang W, Luo T. Efficacy analysis of pedicle screw internal fixation of fractured vertebrae in the treatment of thoracolumbar fractures. Experimental and Therapeutic Medicine. 2013;5:678-82.

26. Öztrürk I, Ertürer E, Sönmez MM, Sari S, Seker A, Seçkin MF. Early mobilization with customized TLSO brace in thoracolumbar burst fracture. Acta Orthop Traumatol Rurc. 2012:46(5):373-8.

\section{Submit your manuscript to a SpringerOpen ${ }^{\circ}$ journal and benefit from:}

- Convenient online submission

- Rigorous peer review

- Open access: articles freely available online

- High visibility within the field

- Retaining the copyright to your article

Submit your next manuscript at $\boldsymbol{\nabla}$ springeropen.com 